\title{
Giemsa N-banding Polymorphism in Six Botanical Varieties and Six Cultivars of Barley, Hordeum vulgare L.
}

\author{
Ahsan A. Vahidy', Qamar Jahan ${ }^{1}$ and Bushreen Jahan ${ }^{2}$ \\ ${ }^{1}$ Department of Genetics, University of Karachi, Karachi-75270, \\ Pakistan \\ ${ }^{2}$ Department of Botany, University of Karachi, Karachi-75270, \\ Pakistan
}

Accepted April 9, 1993

Karyotype analysis is considered an important method for genome analysis. Among the members of Triticeae the most extensively studied genera include Triticum, Aegilops, Hordeum and Secale (Giorgi and Bozzini 1969, Lange and Jochemsen 1971, Vosa 1974, 1976). A karyotype of Hordeum vulgare chromosomes has been constructed after taking in to consideration several variables by Fukui et al. 1987. The problem of identification has arisen because barley chromosome 1-4 are not distinguished easily by conventional karyotype techniques and identification subsequent to rearrangements such as interchanges is also uncertain. The application of the Giemsa banding technique to barley chromosomes facilitated the identification of individual chromosomes based on their characteristic heterochromatic banding pattern (Fukui and Kakeda 1990).

An intervarietal polymorphism of heterochromatin distribution was confirmed by the banding technique. The technique may also be used to study the pedigree, chromosomal aberrations like translocation (Jahan et al. 1990), and as a source of the varietal descriptor. LindeLaursen (1978a) reported polymorphism of the Giemsa C-banding pattern using twenty lines of barley, representing different growth habits (spring/winter type) and spike characteristics (2-rowed/6-rowed) of different age and different geographical regions. Linde-Laursen (1978b) stated that each of chromosomes 1 to 4 and each of the telocentric chromosomes could be identified by their particular C-banding. Singh and Tsuchiya $(1981,1982)$ identified and designated seven complete chromosomes and nine telocentric chromosomes in telotrisomics of barley by an improved Giemsa N-banding technique. Kakeda et al. (1991) reported the heterochromatic differentiation in barley chromosomes by $\mathrm{C}$ - and $\mathrm{N}$-banding techniques in four two-rowed barley cultivars, 'New Golden', 'Shin Ebisu-16', 'Betzes' and 'Emir'.

The present study was undertaken to determine the Giemsa $\mathrm{N}$-banding polymorphism in the several botanical varieties and cultivars of barley.

\section{Materials and methods}

The sources of the germplasm used in this study are listed in Table 1. The plants are as per identification by the respective sources. Seeds were germinated in the Petri dishes, lined with moist filter paper, kept in the dark at room temperature for about $72 \mathrm{hr}$. Root tips were harvested in late morning to obtain good mitotic index and were transferred to another Petri dish for the pretreatment, which was kept in dark for $2.5-3.0 \mathrm{hr}$ as described by Jahan and Vahidy (1989). The pretreatment solution was a mixture of $0.05 \%$ colchicine, $0.025 \% 8$ Hydroxyquinoline and DMSO, as described by Mujeeb-Kazi and Miranda (1985). The root tips were fixed in $0.2 \%$ acetocarmine and stored for two days in the refrigerator at $4{ }^{\circ} \mathrm{C}$. The use of $0.2 \%$ acetocarmine helped in getting a good spread of the chromosomes for banding. The meristematic region of the freshly stained root tips was squashed in $45 \%$ acetic acid. 
The prepared slides were viewed under a phase contrast microscope; and cover glasses were removed by liquid nitrogen. The slides were treated for $10-15$ min with $45 \%$ acetic acid at $60^{\circ} \mathrm{C}$, air dried and kept at room temperature for 2-3 days. N-banding was carried out by treating the slides with $\mathrm{NaH}_{2} \mathrm{PO}_{4}\left(2 \mathrm{M}\right.$ ) solution $\left(\mathrm{pH} \mathrm{4.0)}\right.$ for $25-26$ min at $85-86^{\circ} \mathrm{C}$ (Jahan et al. 1990). Slides were then washed 3-4 times in deionized water and stained with 4-5\% Giemsa (FLUKA NO. 48900) in a standard phosphate buffer solution, pH 6.8 for 30$45 \mathrm{~min}$ at room temperature, air dried for 2-3 days and mounted with Canada balsam. At least five cells were screened and the cells with good spreads and bands selected for photomicrography. Chromosomes were classified on the basis of the criteria of Fukui and Kakeda (1990).

\section{Results and discussion}

Mitotic chromosomes of barley, Hordeum vulgare L. in the six botanical varieties and six cultivars were studied by the Giemsa $\mathrm{N}$-banding technique. The idiograms of the Giemsa $\mathrm{N}$-banding patterns are shown in Figs. 1 and 2, which contain the bands that were visible in

Table 1. Investigated varieties and cultivars of barley, Hordeum vulgare $\mathrm{L}$.

\begin{tabular}{|c|c|c|}
\hline Botanical variety/cultivar & Germplasm source & Accession numbers \\
\hline $\begin{array}{l}\text { Convar. deficiens (Steudel.) Mansf. } \\
\text { var. capticum (Vav. Mansf.) }\end{array}$ & $\begin{array}{l}\text { Okol. Botanischer } \\
\text { Garten, der Univ. } \\
\text { Bayreuth, Germany }\end{array}$ & 614-1991 \\
\hline $\begin{array}{l}\text { Convar. distichon (L.) Alef. } \\
\text { var. brunnei-nudum (Vav. et Orlov) } \\
\text { Mansf. }\end{array}$ & - do - & $615-1991$ \\
\hline $\begin{array}{l}\text { Convar. distichon (L.) Alef. } \\
\text { var. erectum (Rode) Alef. }\end{array}$ & - do & $616-1991$ \\
\hline $\begin{array}{l}\text { Convar. distichon (L.) Alef. } \\
\text { var. melanocrithon Koern. }\end{array}$ & - do - & $597-1989$ \\
\hline $\begin{array}{l}\text { Convar. vulgare } \\
\quad \text { var. leiorrhynchum Koern. }\end{array}$ & - do - & 604-1989 \\
\hline $\begin{array}{l}\text { Convar. vulgare } \\
\quad \text { var. parallelum Koern. }\end{array}$ & - do - & $607-1989$ \\
\hline Hordeum vulgare cv. 'CM-67' & CIMMYT, MEXICO & $55-1987$ \\
\hline H. vulgare cv. 'Atlas- 68 ' & - do - & $56-1987$ \\
\hline H. vulgare cv. 'B-83068' & PAEC, PAKISTAN & $73-1987$ \\
\hline H. vulgare cv. 'PRB-3' & - do - & $74-1987$ \\
\hline H. vulgare cv. 'H-62' & - do - & $68-1987$ \\
\hline H. vulgare cv. 'H-83' & NARC, PAKISTAN & $83-1988$ \\
\hline
\end{tabular}

the majority of metaphases. Very small bands observed infrequently were not included. The majority of $\mathrm{N}$-bands recognized in all varieties/cultivars were centromeric and intercalary positions. The latter were mostly proximal than distal. No telomeric dark bands were found at all. The heteromorphy was the result of variation in band size and in the presence/absence of a band. The heteromorphic bands seemed to be unevenly distributed over chromosomes and chromosome regions. Unstable N-bands observed in the present studies are summarized in Table 2.

Chromosome 1 is a median chromosome with a long arm carrying a centromeric band, 1HLI.1 while the short arm had a centromeric band (1HSI.1) and two intercalary bands (1 HS2.1, 1HS2.3). However, in vars. brunnei-nudum and capticum, and cvs. 'Atlas-68', 'B83068 ' and ' $\mathrm{H}-83$ ' the band, 1 HS2.3 was not found. Chromosome 2 is the longest in the barley chromosome complement. It comprises of light bands as compared to those on other chromosomes. In vars. brumnei-nudum, erectum and melanocrithon both arms showed centromeric bands (2HS1.1, 2HL1.1) and intercalary bands (2HS1.3, 2HL2.1, 2HS2.1 and 2HL3.1). The 

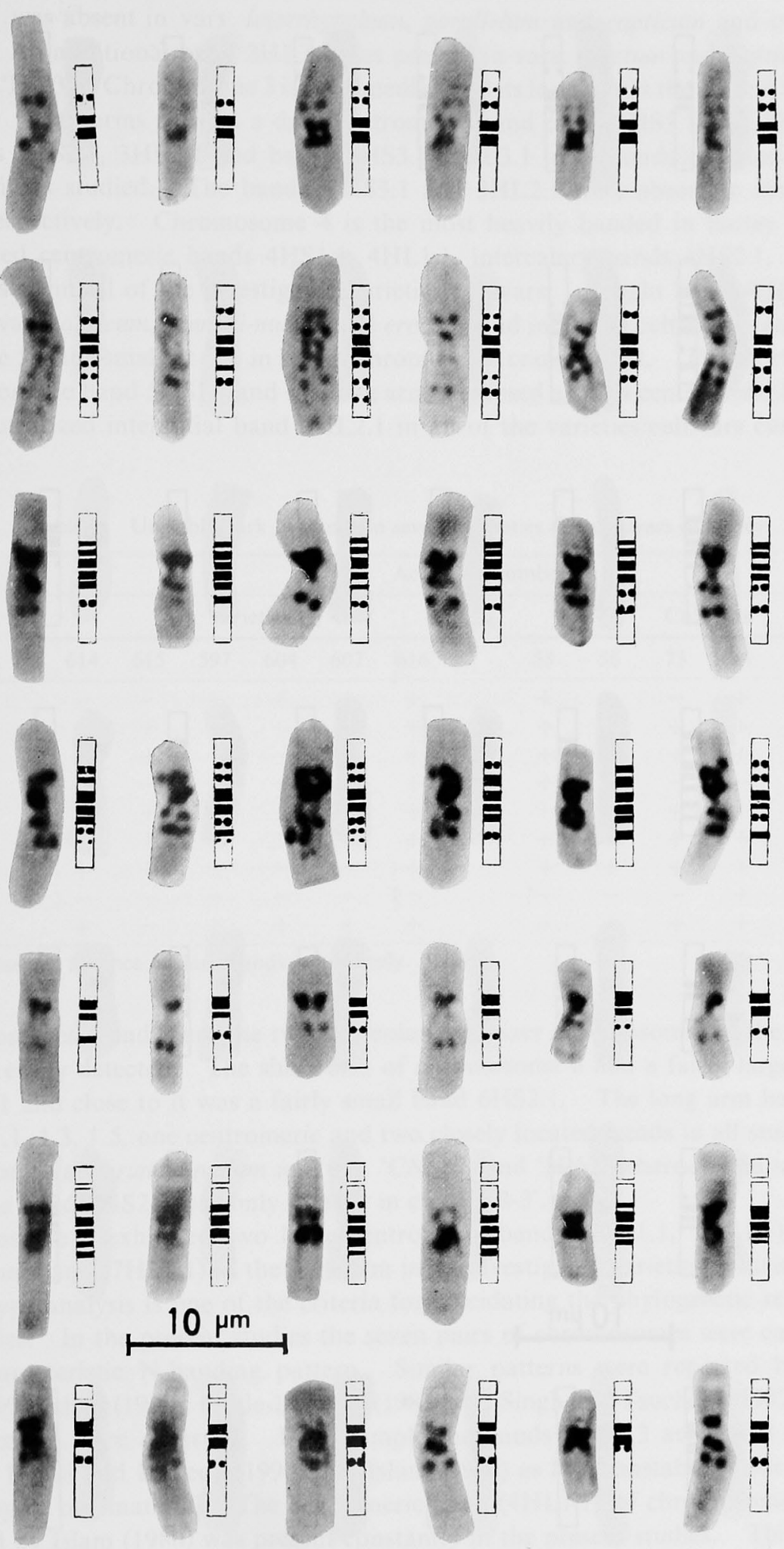

Fig. 1. N-banding polymorphism in barley, Hordeum vulgare L. in six varieties viz. capticum, brunnei-nudum, erectum, melanocrithon, leiorrhynchum, and parallelum arranged in columns from left to right. The chromosomes (1 to 7) are arranged in rows from top to bottom. 

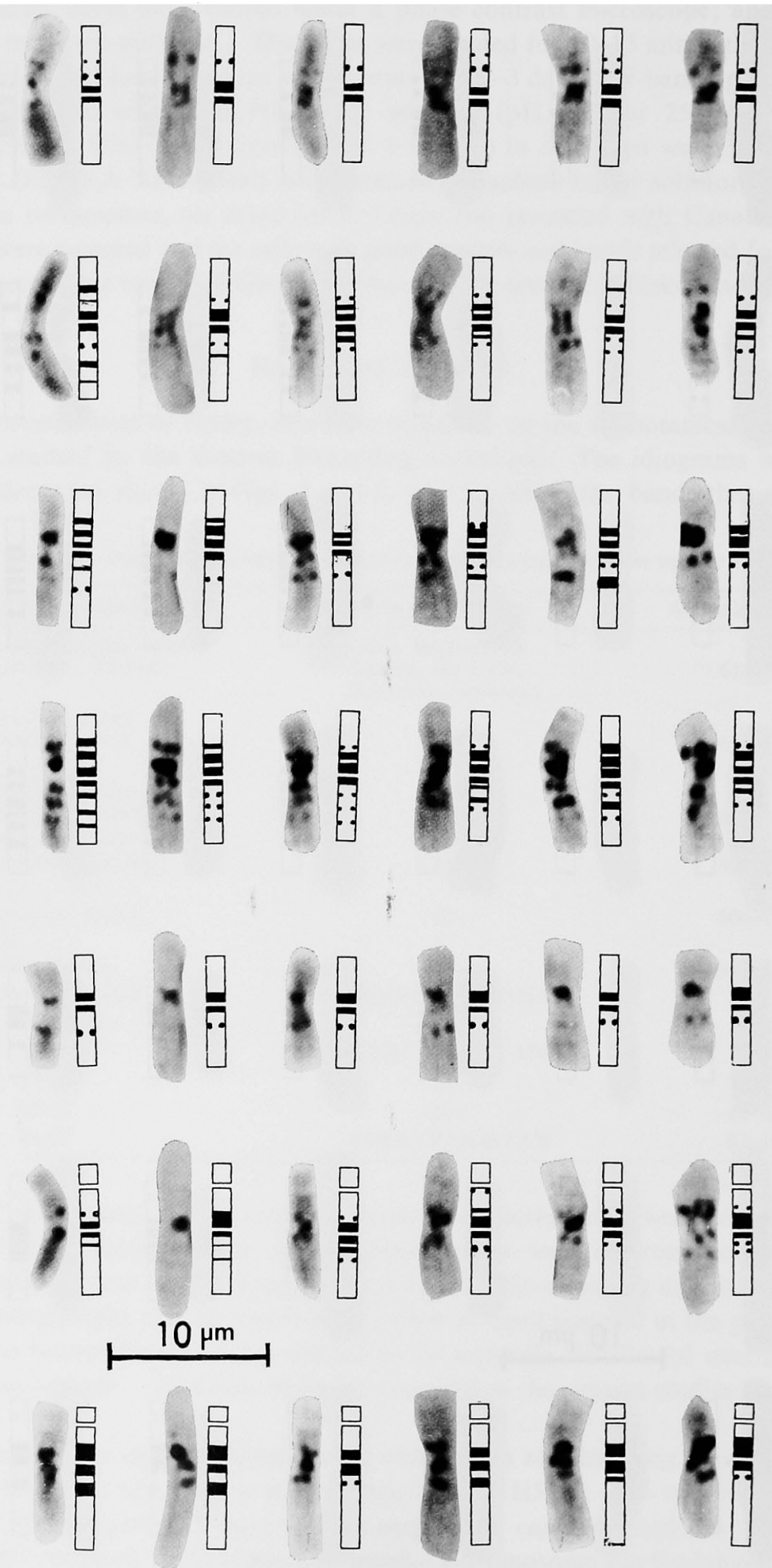

Fig. 2. N-banding polymorphism in barley, Hordeum vulgare L. in six cultivars viz. 'CM-67', 'Atlas-68', 'B-83068', 'PRB-3', 'H-62' and 'H-83' arranged in columns from left to right. The chromosomes ( 1 to 7 ) are arranged in rows from top to bottom. 
band 2HS2.1 was absent in vars. leiorrhynchum, parallelum and capticum and cvs. 'Atlas-68' and 'H-83'. An additional band $2 \mathrm{HL} 3.3$ was present in vars. erectum and capticum and cvs. 'CM-67' and 'H-83'. Chromosome 3 is a submedian and its long arm is the second longest in the complement. Both arms showed a dark centromeric band each, 3HS1.1 and $3 \mathrm{HL} 1.1$; intercalary bands $3 \mathrm{HS} 2.1,3 \mathrm{HL} 2.1$ and bands $3 \mathrm{HS} 3.1,3 \mathrm{HL} 3.1$ in the middle region in all of the varieties/cultivars studied. The bands, 3HS3.1 and 3HL2.1 were absent in cvs. 'H-62' and 'Atlas-68', respectively. Chromosome 4 is the most heavily banded in barley complement. Darkly stained centromeric bands 4HS1.1, 4HL1.1, intercalary bands 4HS2.1, 3.1, 4HL2.1, 3.1 were present in all of the investigated varieties/cultivars. A light band 4HL4.1 was also observed in var. capticum, brunnei-nudum and erectum and in all the cultivars except cv. ' $\mathrm{H}-83$ '. Chromosome 5 is the smallest one in barley chromosome complement. The short arm showed a large centromeric band 5HS1.1 and the long arm possessed a small centromeric band 5HL1.1 and a medium sized interstitial band 5HL2.1 in all of the varieties/cultivars curvently investigated.

Table 2. Unstable dark N-Bands in several varieties and cultivars of barley

\begin{tabular}{|c|c|c|c|c|c|c|c|c|c|c|c|c|}
\hline \multirow{3}{*}{ N-bands } & \multicolumn{12}{|c|}{ Accession numbers } \\
\hline & \multicolumn{6}{|c|}{ Varieties } & \multicolumn{6}{|c|}{ Cultivars } \\
\hline & 614 & 615 & 597 & 604 & 607 & 616 & 55 & 56 & 73 & 74 & 68 & 83 \\
\hline $1 \mathrm{HS} 2.3$ & - & - & + & + & + & + & + & - & - & + & + & - \\
\hline 2HS1.3 & - & + & + & - & - & + & + & + & + & + & + & + \\
\hline 2HS2.1 & - & + & + & - & - & + & + & - & + & + & + & - \\
\hline $2 \mathrm{HL} 3.3$ & + & - & - & - & - & + & + & - & - & - & - & + \\
\hline 3HS3.1 & + & + & + & + & + & + & + & + & + & + & - & + \\
\hline 3HL2.1 & + & + & + & + & + & + & + & - & + & + & + & + \\
\hline 4HL4.1 & + & + & - & - & - & + & + & + & + & + & + & - \\
\hline $6 \mathrm{HS} 2.3$ & - & - & - & - & - & - & - & - & - & + & - & - \\
\hline $6 \mathrm{HL} 1.5$ & + & - & + & + & + & + & - & + & + & + & - & + \\
\hline
\end{tabular}

,+- : presence, absence of dark bands respectively.

Chromosomes 6 and 7 are the two nucleolar organizer chromosomes in the complement, thus can be easily detected. The short arm of chromosome 6 had a fairly large centromeric band 6HS1.1 and close to it was a fairly small band 6HS2.1. The long arm had three small bands $6 \mathrm{HL} 1.1,1.3,1.5$, one centromeric and two closely located bands in all studied varieties/ cultivars except var. brunnei-nudum and cvs. 'CM-67' and 'H-62' where the band 6HL1.5 was absent. The band $6 \mathrm{HS} 2.3$ was only present in cv. 'PRB-3'.

Chromosome 7 exhibited two large centromeric bands (7HS1.1, 7HL1.1) and a fairly large proximal band (7HL2.1) in the long arm in all investigated varieties/cultivars.

Karyotype analysis is one of the criteria for elucidating the phylogenetic relationships of related species. In the present studies the seven pairs of chromosomes were easily identified by their characteristic N-banding pattern. Similar patterns were reported by Fukui and Kakeda (1990), Islam (1980), Linde-Laursen (1981) and Singh and Tsuchiya (1982). However, minor differences were observed. For example the bands 4HL2.3 and 7HS1.3 which were reported by Fukui and Kakeda (1990) and Islam (1980) as faint unstable bands were not observed in any of our material. The centromeric band (4HL1.1) of chromosome 4 which was not reported by Islam (1980) was present constantly in the present studies. This agrees fairly well with the results of Fukui and Kakeda (1990) and Singh and Tsuchiya (1982).

Band heteromorphy affords the possibility of using bands simultaneously with genetic markers in cytogenetic studies. Comparative idiogram for different varieties of Hordeum 
shows some intervarietal variations in the karyotypes (Fig. 1). It is evident from Fig. 1 that vars. leiorrhynchum and parallelum are similar in their karyotypes by having 2-6 similar bands. Chromosome 1, 3, 5, 6 and 7 of vars. erectum and melanocrithon have almost same banding patterns, but they differ with each other by having $2 \mathrm{HL} 3.3$ and $4 \mathrm{HL} 4.1$ bands in var. erectum (Table 2). Varieties brunnei-nudum and capticum differ from each other by the presence of $2 \mathrm{HS} 2.1$ band in the former and $2 \mathrm{HL} 3.3,6 \mathrm{HL} 1.5$ bands in the latter variety. They differ from other varieties by the absence of $1 \mathrm{HS} 2.3$ band in them.

In the case of cultivars, currently studied, two intercalary bands were observed in the short arm of chromosome 1. The band 1HS2.3 was present in cultivars 'CM-67', 'PRB-3' and ' $\mathrm{H}$ 62' and absent in the other three cultivars (Table 2, Fig. 2). These types of bands were also observed by the Fukui and Kakeda (1990) in the haploid line of cv. 'New Golden'. The band $2 \mathrm{HS} 1.3$ was present in all cultivars, the band $2 \mathrm{HS} 2.1$ was present in 'CM-67', 'B-83068', 'PRB3 ' and ' $\mathrm{H}-62$ ' and band $2 \mathrm{HL} 3.3$ was present in 'CM-67' and ' $\mathrm{H}-83$ '. The distal interstitial bands 3HS3.1, 3HL2.1 were missing only in 'H-62' and 'Atlas-68', respectively. The band 4HL4.1 was absent in $\mathrm{cv}$. 'H-83'. The band 6HS2.3 was present only in 'PRB-3'. The band $6 \mathrm{HL1} .3$ which was reported as inconsistent band by the other workers was observed in all the twelve cultivars and varieties. The band $6 \mathrm{HL} 1.5$ was present in 'Atlas-68', 'B-83068', 'PRB-3' and 'H-83', and absent in other two cultivars (Fig. 2).

The results indicated that all varieties of Hordeum investigated had characteristic banding pattern and polymorphism was evident on 1,2, 4 and 6 chromosomes. Among the cultivars the $\mathrm{N}$-banding polymorphism was observed in interstitial regions of chromosomes $1,2,3$ and 6. On the basis of these results it can be concluded that both varieties and cultivars may be identified due to their N-banding patterns.

The major heterochromatin polymorphism does not occur in barley, probably because it is highly self pollinated crop. However, minor differences in the banding pattern have been observed. The $\mathrm{N}$-bands described here correspond to polyprimidine-polypurine (GAA)m (GAG)n sequences. Since all chromosomes of barley did not band terminally through $\mathrm{N}$ banding, thus it may be inferred that the terminal ends are devoid of such sequences.

Barley chromosomes numbered 1 to 7 here are now labeled as $7 \mathrm{H}, 2 \mathrm{H}, 3 \mathrm{H}, 4 \mathrm{H}, 1 \mathrm{H}, 6 \mathrm{H}$ and $5 \mathrm{H}$ respectively (Heun et al. 1991) due to their homoeology to wheat chromosomes.

\section{Summary}

Mitotic chromosomes in six botanical varieties and six cultivars of barley, Hordeum vulgare L. were studied by Giemsa N-banding technique. Chromosomes 1 and 4 are metacentric and thus their short (S) and long (L) arms can not be differentiated through conventional staining method. These were easily differentiated on the basis of the bands on them. The classification of the bands was in accordance to Generalized Cytological Nomenclature of Cereal Chromosomes (GCNCC). Minor differences in the banding pattern among the studied varieties/cultivars were observed. The results indicated that all varieties of Hordeum investigated had characteristic banding pattern and polymorphism was evident on 1, 2, 4 and 6 chromosomes. Among the cultivars $\mathrm{N}$-banding polymorphism was observed in interstitial regions of chromosomes $1,2,3$ and 6 . On the basis of these results it can be concluded that both varieties and cultivars may be identified due to their $\mathrm{N}$-banding patterns.

\section{Acknowledgement}

We are grateful to various agencies and research centers listed in Table 1 for the supply of seed material. 


\section{References}

Fukui, K. and Kakeda, K. 1990. Quantitative karyotyping of barley chromosomes by image analysis methods. Genome 33: 450-458.

-, -, and Matsuno, T. 1987. Karyotypes of barley chromosomes constructed by several parameters. Barley Genet. 5: 415-422.

Giorgi, B. and Bozzini, A. 1969. Karyotype analysis in Triticum. III. Analysis of the presumed diploid progenitors of polyploid wheats. Caryologia $22: 279-288$.

Heun, M., Kennedy, A. E., Anderson, J. A., Lapitan, N. L. V., Sorrells, M. D. and Tanksley, S. D. 1991. Construction of a restriction fragment length polymorphism map for barley (Hordeum vulgare). Genome 34: 437-447.

Islam, A. K. M. R. 1980 . Identification of Wheat-Barley addition lines with N-banding of chromosomes. Chromosoma (Berl.) 76: 365-373.

Jahan, Q. and Vahidy, A. A. 1989. Karyotype analysis of hexaploid wheat, Triticum aestivum L. cv. 'Sarsabz'. J. Isl. Aca. Sci. 2: 179-181.

-, Ter-Kuile, N., Hashmi, N., Aslam, M., Vahidy, A. A. and Mujeeb-Kazi, A. 1990. The status of the 1B/1R translocation chromosome in some released wheat varieties and the 1989 candidate varieties of Pakistan. Pak. J. Bot. 22 (1): 1-10.

Kakeda, K., Fukui, K. and Yamagata, H. 1991. Heterochromatic differentiation in barely chromosomes revealed by $\mathrm{C}$ - and N-banding techniques. Theor. Appl. Genet. 81: 144-150

Lange, W. and Jochemsen, G. 1971. Karyotypes, nucleoli, and amphiplasty in hybrids between Hordeum vulgare $\mathrm{L}$. and $H$. bulbosum $\mathrm{L}$. Genetica 46: 217-233.

Linde-Laursen, I. 1978a. Giemsa C-banding of barley chromosome. I. Banding pattern polymorphism. Hereditas 88: 55-64.

- 1978b. Giemsa C-banding of barley chromosome. II. Banding patterns of trisomics and telotrisomics. Hereditas 89 : $37-41$.

- 1981. Giemsa banding patterns of the chromosomes of the cultivated and wild barleys. Barley Genet. 4: 786-795.

Mujeeb-Kazi, A. and Miranda, J. L. 1985. Enhanced resolution of somatic chromosome constrictions as an aid to identifying intergeneric hybrids among some Triticeae. Cytologia 50: 701-709.

Singh, R. J. and Tsuchiya, T. 1981. Identification and designation of barley chromosomes by Giemsa banding technique: a reconsideration. Z. Planzenzucht 86: 336-340.

- and - 1982. Identification and designation of telocentric chromosomes in barley by means of Giemsa N-banding technique. Theor. Appl. Genet. 64: 13-24.

Vosa, C. G. 1974. The basic karyotype of rye (Secale cereale) analysed with Giemsa and fluorescence methods. Heredity 33: $403-408$.

- 1976. Chromosome banding patterns in cultivated and wild barley. (Hordeum spp.). Heredity 37: 395403. 